\title{
Association of Temperament, Family Environment and Personality Traits with the Symptoms of Depression and Substance Abuse Disorder: An Exploratory Research
}

\author{
Kaukab Imam, Deoshree Akhouri, Shravan Kumar
}

\begin{abstract}
Depression and Substance Abuse Disorder though being a very serious psychological illness yet are very commonly being experienced in the present scenario. There is a significant relationship between depression/substance abuse disorder and psycho-social factors. Aim of the present study is to see the association of temperament, family environment and personality traits with the symptoms of Depression and Substance Abuse Disorder patients. The researchers have tried their best to figure out the factors that are responsible for experiencing depression or substance abuse disorder. Significance of the study: The present study is done with the purpose of finding the relationship between factors like Temperament, Family Environment and Personality Traits and psychiatric symptoms being experienced by depressive patients and substance abuse disorder patients and pointing out which factor plays a significant role in maintaining symptoms of depression and substance abuse disorder. Sample: Sample of 200 clinically diagnosed patients was taken from JNMC, AMU and Shantiratn Foundation, Delhi in which 100 were depressive disorder patients and 100 were substance abuse disorder patients. Purposive sampling method was used for the sample selection. Tools: Tools used for the present study are Becks Depression Inventory, The Severity Dependence Scale, Family Environment Scale, NEO Five Factor Inventory, and Dimension of Temperament Scale. The statistical analyses were done with the help of Statistical Package for Social Science-20 (SPSS-20). For analyses of data raw score was converted to standard score then mean and standard deviation were calculated. Result: For Depression patients: The patient scored low mean on dimension sociability, secretiveness, reflective, vigorous, cooperative, warmth, aggressive, tolerance. The patients scored high mean on domain Neuroticism. The patients had Conflict Oriented family profile according to the patient's perception. For Substance Abuse disorder patients: The patients scored low mean on dimension vigorous, warmth, tolerance. The patient scored high mean on domain Neuroticism. According to the patient's perception regarding their family environment, the family had a Conflict Oriented family. Conclusion: After sufficient analysis and an in depth study followed by necessary interpretation of the results obtained regarding the underlying variables it can be successfully concluded that the variables (Temperament, Family environment and Personality traits) and the psychiatric symptoms of depression and substance abuse disorder are interlinked/associated with each other.
\end{abstract}

Manuscript received on 25 July 2021 | Revised Manuscript received on 08 August 2021 | Manuscript Accepted on 15 August 2021 | Manuscript published on 30 August 2021.

* Correspondence Author

Dr. Kaukab Imam*, Ph. D. Psychology, Aligarh Muslim University (AMU), Aligarh (U.P), India.

Dr. Deoshree Akhouri, Associate Professor, Department of Psychiatry, JNMCH, AMU, Aligarh (U.P), India.

Dr. Shravan Kumar, Senior Resident, JNMCH, AMU, Aligarh (U.P), India.

(c) The Authors. Published by Lattice Science Publication (LSP). This is an open access article under the CC-BY-NC-ND license (http://creativecommons.org/licenses/by-nc-nd/4.0/)

Keywords: Depression, Substance Abuse Disorder, Temperament, Family Environment, Personality traits, NEOFFI.

\section{INTRODUCTION}

In the words of Psychology, psychological disorder or mental disorder from which one suffers is due to the abnormal behaviour done by the person. The extreme reaction to the problems and stresses of life being faced by a person leads one to suffer from psychological disorder or mental disorder.

From the wide spectrum of reasons behind a person suffering from depression and substance abuse disorder, the areas of concern for the present study are temperament, family environment and personality traits.

Temperament is the emotion, ego, the frame of mind, intellect, inner nature, mentality, peculiarity, etc of an individual that clubbed together forms a personality of an individual such as introversion and extroversion, shyness, aggressive, euphoric, etc that are unique to individual to individual. Temperament is often regarded as innate rather than learned. Temperament is said to be genetically inherited, though it is also gets effected by the experience of every individual. Allport $(1937,1961)$ approach points several aspects to the centrality of temperament in understanding personality.

Personality of an individual is a combination of thoughts, feelings, emotions and behaviours. It is a unique pattern of behaviour which decides or is responsible for the adaptation to the environment. According to Allport (1937) mention both inner quality and behaviour but emphasized on inner quality. Personality traits are characteristics that are possessed by an individual. When the individual behaves in a particular manner across different situation and time, then that behaviour of the individual is regarded as their characteristics and the individual is said to posses' particular type of personality.

One other factor which is family environment plays a very significant and crucial role in every individual's life. The manner in which the upbringing of a child done says a lot about the kind of personality he/she will have. The atmosphere at home, the way one is treated at home has a powerful impact on an individual's mind and this builds a personality that one bears for a long period of time unless until one deliberately makes an effort to make changes in it.

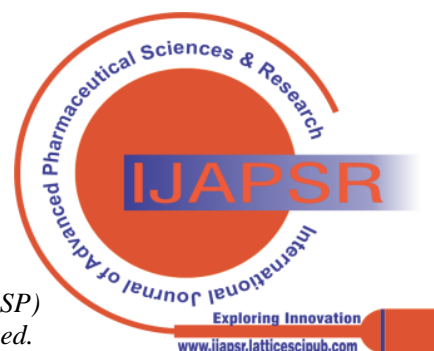


All these factors (temperament, family environment, and personality traits) are directly or indirectly aggravate the person for future depression and substance abuse.

Depression is a state experiencing persistent sadness for a quiet long period of time. A person in depression has a loss of interest in activities that were once enjoyed. It can lead to a variety of emotional and physical problems.

Substance Use disorder (SUD) is a condition in which the use of one or more substance leads to a clinically significant impairment or distress.

Many studies have been done to find out the association between the variables mentioned above. E. Jenna Robison, Stewart A. Shankman, and Brian R. McFarland (2009) concluded that low level of positive personality traits had a unique association with depression and increased level of negative personality traits leads to early onset of depression.

Markus Jokela, and Liisa Keltikangas-Jarvinen (2011) conducted a study to see the association between low socioeconomic status and depressive symptoms depends on temperament and personality traits. Through the study they found that low socioeconomic status (education, occupation status, and income) is associated with high persistent negative association with depressive symptoms.

Tara Gilhooly, Andrea J Bergman, Joshua Stieber, and Elissa J Brown (2018) in their study titled Posttraumatic stress disorder symptoms, family environment, and substance abuse symptoms in emerging adults; found that PTSD symptoms and substance abuse symptoms were positively correlated with each other and family environment was moderately associated with the substance abuse and PTSD symptoms.

Angelina R Sutin, Yannick Stephan, Martina Luchetti, and Antonio Terracciano (2019) conducted a study to see the association between personality traits and persistent pain and opioid medication use, found out that personality traits are psychological characteristics that regulates the likelihood of persistent pain and opioid medication use.

All these findings motivated us to do present research on Depression and substance abuse disorders patients.

\section{SIGNIFICANCE OF THE STUDY}

The present study is done with the purpose of finding the relationship between factors like Temperament, Family Environment and Personality Traits and psychiatric symptoms being experienced by depressive patients and substance abuse disorder patients and pointing out which factor plays a significant role in maintaining symptoms of depression and substance abuse disorder.

\section{Objectives:}

1. To examine how temperament is associated to psychiatric symptoms in Depression.

2. To examine how family environment is associated to psychiatric symptoms in Depression.

3. To examine how personality traits are associated to psychiatric symptoms in Depression.

4. To examine how temperament is associated to psychiatric symptoms in Substance Abuse Disorder.

5. To examine how family environment is associated to psychiatric symptoms in Substance Abuse Disorder.

6. To examine how personality traits are associated to psychiatric symptoms in Substance Abuse Disorder.

\section{Hypotheses:}

H1. Temperament will be associated with the psychiatric symptoms in depression.

H2. Influence of Family environment plays a role in psychiatric symptoms in depression.

H3. Personality trait will be associated with the psychiatric symptoms in depression.

H4. Temperament will be associated with the psychiatric symptoms in substance abuse disorder patients.

H5. Influence of Family environment plays a role in psychiatric symptoms in substance abuse disorder.

H6. Personality trait will be associated with the psychiatric symptoms in substance abuse disorder patients.

\section{INCLUSION AND EXCLUSION CRITERIA}

\section{Inclusion criteria}

Age:

$$
\text { 20-40 years }
$$

Gender: Only Male

\section{Duration of Illness: 1 year}

Patients:

Already Clinically diagnosed patients of Depression and Substance abuse Disorder were taken for the present research.

Severity of Disorder: Moderate Level of Depression Moderate to Severe level of

\section{Substance Abuse Disorder}

\section{Exclusion Criteria}

- $\quad$ Female and Transgender.

\section{Tools used:}

1. Becks Depression Inventory.

2. The Severity Dependence Scale.

3. Family Environment Scale.

4. NEO Five Factor Inventory.

5. Dimension of Temperament Scale.

\section{Sample:}

Sample of 200 clinically diagnosed patients was taken from OPD, Department of Psychiatry, JNMC, AMU and a rehabilitation centre Shantiratn Foundation, Delhi in which 100 were depressive disorder patients and 100 were substance abuse disorder patients. Purposive sampling method was used for the sample selection. The patients who were taken for the present study were already diagnosed by psychiatrist and some are admitted in their treatment centre.

\section{Procedure:}

For data collection rehabilitation centre and hospital were approached. They were diagnosed by psychiatrist as per DSM-5 criteria. According to inclusion and exclusion criteria patients were selected through purposive sampling method. Patients who gave consent for the study were included in present research. The patients were given above mentioned questionnaires to fill.

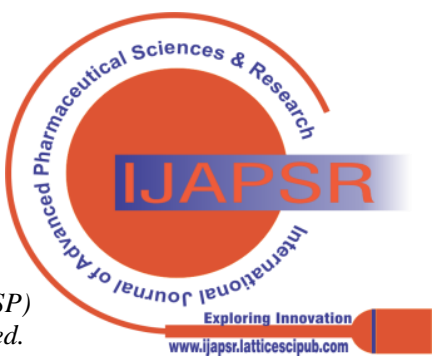




\section{Statistical Analyses:}

The statistical analyses were done with the help of Statistical Package for Social Science-20 (SPSS-20). For socio-demographic analysis percentage was calculated. For further analyses of data raw score was converted to standard score, mean and standard deviation was calculated.

\section{RESULT}

Table-1: Showing the Socio-demographic details of all the patients (\%age).

\begin{tabular}{|c|c|c|c|}
\hline & Criteria & $\begin{array}{l}\text { Depression patients } \\
\quad(n=100) ; \%\end{array}$ & $\begin{array}{c}\text { Substance Abuse } \\
\text { disorder patients } \\
(n=100) ; \%\end{array}$ \\
\hline \multirow[t]{2}{*}{ Age } & $20-30$ & $35 \%$ & $50 \%$ \\
\hline & $31-40$ & $65 \%$ & $50 \%$ \\
\hline \multirow{2}{*}{ Education } & Literate & $70 \%$ & $70 \%$ \\
\hline & Illiterate & $30 \%$ & $30 \%$ \\
\hline \multirow{2}{*}{ Marital status } & Married & $40 \%$ & $50 \%$ \\
\hline & Unmarried & $60 \%$ & $50 \%$ \\
\hline \multirow{2}{*}{ Residence } & Rural & $15 \%$ & $40 \%$ \\
\hline & Urban & $85 \%$ & $60 \%$ \\
\hline
\end{tabular}

Table no-1, shows the socio-demographic details that indicates the percentage of depression patients and substance abuse disorder patients on the inclusive criteria.

Table-2: Shows the Mean score and Standard deviation score (SD) on Beck's Depression Inventory (BDI) for Depression patients.

\begin{tabular}{|c|c|c|}
\hline Mean & N & SD \\
\hline 23.01 & 100 & 7.63 \\
\hline
\end{tabular}

Table-2, indicates that most of the patients scored moderate level of depression on Beck's Depression Inventory (BDI) $(\mathrm{m}=23.01, \mathrm{SD}=7.63)$.

Table-3: Shows the Mean scores and Standard deviation scores (SD) on Dimensions of Temperament Scale (DTS) for Depression patients.

\begin{tabular}{|c|c|c|c|}
\hline $\begin{array}{c}\text { Dimensions } \\
(\mathrm{N}=100)\end{array}$ & $\mathbf{N}$ & Mean & SD \\
\hline Sociability & \multirow[b]{8}{*}{100} & 9.68 & 1.59 \\
\hline Ascendant & & 7.36 & 1.56 \\
\hline Secretiveness & & 7.43 & 1.77 \\
\hline Reflective & & 7.97 & 1.64 \\
\hline Impulsivity & & 5.46 & 1.14 \\
\hline Placid & & 8.38 & 1.93 \\
\hline Accepting & & 5.08 & 1.20 \\
\hline Responsible & & 7.23 & 1.30 \\
\hline
\end{tabular}

\begin{tabular}{|c|c|c|}
\hline Vigorous & 10.76 & 2.14 \\
\hline Co-operative & 10.78 & 2.11 \\
\hline Persistence & 6.56 & 1.15 \\
\hline Warmth & 10.88 & 2.43 \\
\hline Aggressiveness & 7.66 & 1.71 \\
\hline Tolerance & 8.49 & 1.97 \\
\hline $\begin{array}{l}\text { Tough- } \\
\text { minded }\end{array}$ & 5.50 & 1.38 \\
\hline
\end{tabular}

Table-3, indicates that the patients with moderate level of depression have low mean score (as discussed in the Dimensions in Temperament Scale (DTS) manual, Table no-6) on dimensions of temperament Sociability ( $M=9.68$, $\mathrm{SD}=1.59)$, Secretiveness $(\mathrm{m}=7.43, \mathrm{SD}=1.77)$, Reflective $(\mathrm{m}=7.97, \quad \mathrm{SD}=1.64)$, Vigorous $\quad(\mathrm{m}=10.76, \quad \mathrm{SD}=2.14)$, Cooperative $(\mathrm{m}=10.78, \mathrm{SD}=2.11)$, Warmth $(\mathrm{m}=10.88, \mathrm{SD}=$ 2.43), Aggressiveness $(\mathrm{m}=7.66, \quad \mathrm{SD}=1.71)$, Tolerance $(\mathrm{m}=8.49$, $\mathrm{SD}=1.89)$. the patients were average on dimensions Ascendant $(\mathrm{m}=7.36, \mathrm{SD}=1.56)$, Impulsivity $(\mathrm{m}=5.46, \mathrm{SD}=1.14)$, Placid $(\mathrm{m}=8.38, \mathrm{SD}=1.93)$, Responsible $(\mathrm{m}=7.23, \quad \mathrm{SD}=1.30), \quad$ Persistence $\quad(\mathrm{m}=6.56, \quad \mathrm{SD}=1.15)$, Tough-minded $(\mathrm{m}=5.50, \mathrm{SD}=1.38)$. The patients scored high mean on dimension Accepting $\mathrm{SD}=1.20)$. $(m=5.08$,

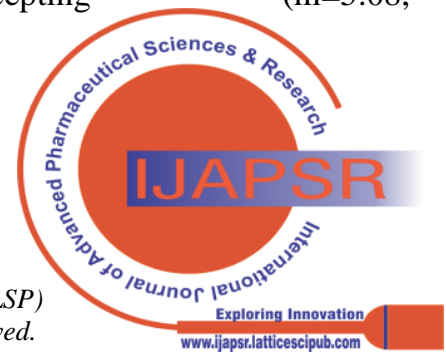


Association of Temperament, Family Environment and Personality Traits with the Symptoms of Depression and Substance Abuse Disorder: An Exploratory Research

Figure-I: Showing the Percentage of Depression patients on different dimensions of Dimension in Temperament Scale (DTS)

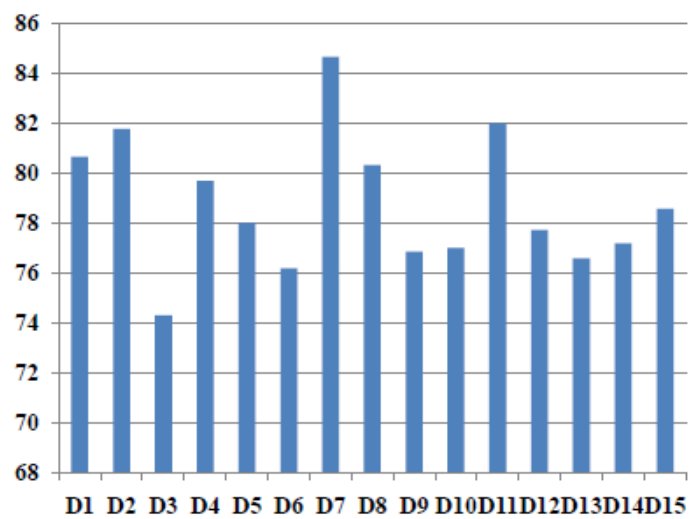

\begin{tabular}{|l|c|}
\hline D1 (Sociability) & $80.66 \%$ \\
\hline D2 (Ascendance) & $81.77 \%$ \\
\hline D3 (Secretiveness) & $74.3 \%$ \\
\hline D4 (Reflective) & $79.7 \%$ \\
\hline D5 (Impulsivity) & $78 \%$ \\
\hline D6 (Placid) & $76.18 \%$ \\
\hline D7 (Accepting) & $84.66 \%$ \\
\hline D8 (Responsible) & $80.33 \%$ \\
\hline D9 (Vigorous) & $76.85 \%$ \\
\hline D10 (Cooperative) & $77 \%$ \\
\hline D11 (Persistence) & $82 \%$ \\
\hline D12 (Warmth) & $77.71 \%$ \\
\hline D13 (Aggressiveness) & $76.6 \%$ \\
\hline D14 (Tolerance) & $77.18 \%$ \\
\hline D15 (Tough-minded) & $78.57 \%$ \\
\hline
\end{tabular}

Table-4: Shows the Mean scores and Standard deviation scores (SD) on NEO-FFI for Depression patients.

\begin{tabular}{|c|c|c|c|}
\hline Dimensions & $\mathbf{N}$ & Mean & SD \\
\hline Neuroticism & \multirow{5}{*}{100} & 26.42 & 6.68 \\
\hline Extraversion & & 23.76 & 7.56 \\
\hline Openness & & 24.81 & 7.55 \\
\hline Agreeableness & & 24.27 & 7.70 \\
\hline Conscientiousness & & 24.19 & 7.71 \\
\hline
\end{tabular}

Table-4, indicates that the patients shows high mean score (as discussed in the NEO-FFI manual, Table no-B4) on domain Neuroticism $(\mathrm{m}=26.42, \mathrm{SD}=6.68)$ and low mean score on domains Extraversion $(\mathrm{m}=23.76, \mathrm{SD}=7.56)$, Openness $(\mathrm{m}=24.81, \mathrm{SD}=7.55)$, Agreeableness $(\mathrm{m}=24.27$, $\mathrm{SD}=7.70)$, Conscientiousness $(\mathrm{m}=24.19, \mathrm{SD}=7.71)$.
Figure- II: Showing the Percentage of Depression patients on domains of NEO-FFI

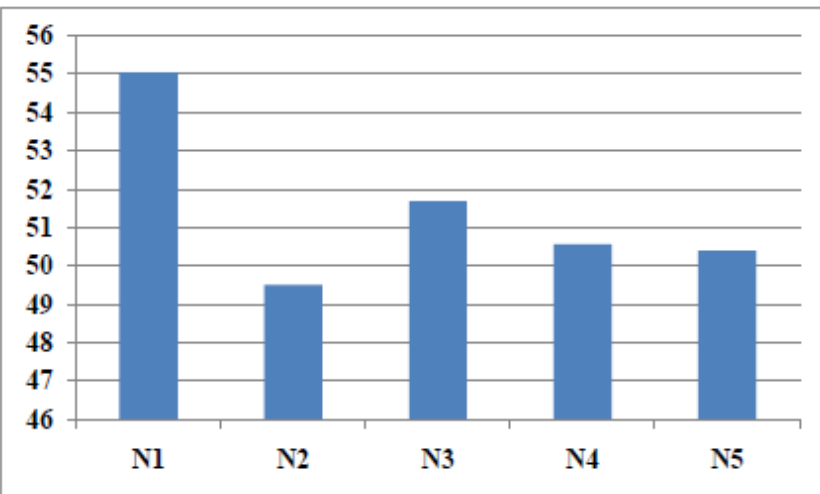

\begin{tabular}{|c|c|}
\hline N1 (Neuroticism) & $55.04 \%$ \\
\hline N2 (Extraversion) & $49.5 \%$ \\
\hline N3 (Openness) & $51.68 \%$ \\
\hline N4 (Agreeableness) & $50.56 \%$ \\
\hline N5 (Conscientiousness) & $50.39 \%$ \\
\hline
\end{tabular}

Table-5: Shows the Mean scores and Standard deviation scores (SD) on Family Environment Scale (FES) for Depression patients.

\begin{tabular}{|c|c|c|c|}
\hline Dimensions & $\mathbf{N}$ & Mean & SD \\
\hline Cohesion & \multirow{10}{*}{100} & 55.04 & 8.37 \\
\hline Expressiveness & & 60.57 & 11.05 \\
\hline Conflict & & 71.48 & 6.81 \\
\hline Independence & & 55.72 & 9.99 \\
\hline $\begin{array}{c}\text { Achievement } \\
\text { Orientation }\end{array}$ & & 59.91 & 8.11 \\
\hline $\begin{array}{l}\text { Intellectual- } \\
\text { Cultural } \\
\text { Orientation }\end{array}$ & & 60.36 & 7.47 \\
\hline $\begin{array}{c}\text { Active- } \\
\text { Recreational } \\
\text { Orientation }\end{array}$ & & 63.10 & 6.12 \\
\hline $\begin{array}{c}\text { Moral- } \\
\text { Religious } \\
\text { Emphasis }\end{array}$ & & 60.45 & 7.94 \\
\hline Organization & & 58.83 & 6.63 \\
\hline Control & & 65.77 & 7.62 \\
\hline
\end{tabular}

Table-5, indicates the mean score and SD of the patients (as discussed in the manual of FES by making few casestudies the base for the analysis and interpretation)

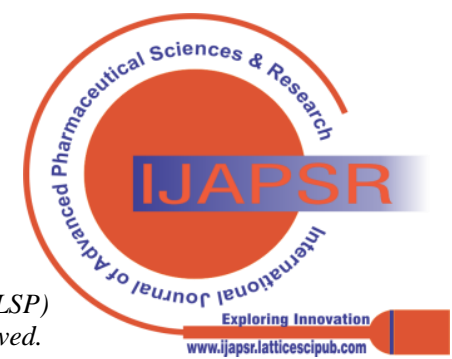


on subscales Cohesion $(\mathrm{m}=55.04, \mathrm{SD}=8.37)$, Expressiveness $(\mathrm{m}=60.57, \mathrm{SD}=11.05)$, Conflict $(\mathrm{m}=71.48$, $\mathrm{SD}=6.81), \quad$ Independence $\quad(\mathrm{m}=55.72, \quad \mathrm{SD}=9.99)$, Achievement Orientation ( $\mathrm{m}=59.91, \mathrm{SD}=8.11)$, IntellectualCultural Orientation $(\mathrm{m}=60.36, \quad \mathrm{SD}=7.47)$, ActiveRecreational Orientation $(\mathrm{m}=63.10, \quad \mathrm{SD}=7.47)$,MoralReligious Emphasis $(\mathrm{m}=60.45, \mathrm{SD}=7.94)$, Organization $(\mathrm{m}=58.83, \mathrm{SD}=6.63)$, Control $(\mathrm{m}=65.77, \mathrm{SD}=7.62)$.

Figure-III: Showing the Percentage of Depression patients on different subscales of FES

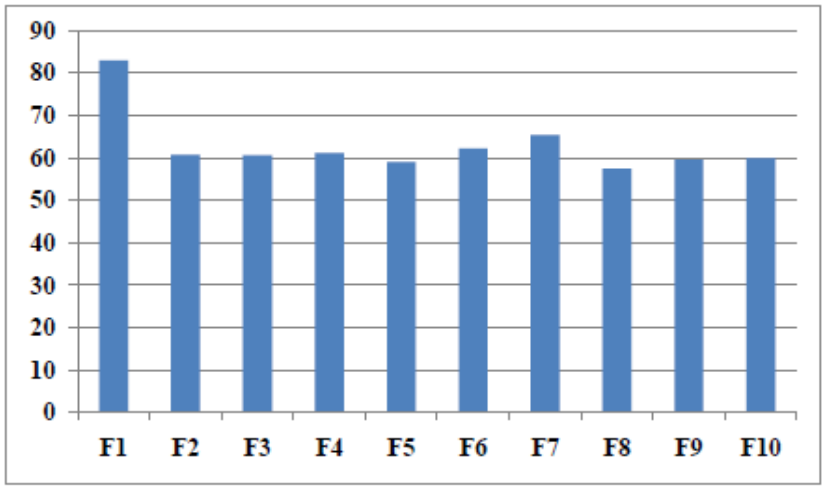

\begin{tabular}{|l|c|}
\hline F1 (Cohesion) & $82.88 \%$ \\
\hline F2(Extraversion) & $60.66 \%$ \\
\hline F3(Conflict) & $60.58 \%$ \\
\hline F4(Independence) & $61.16 \%$ \\
\hline F5(Achievement Orientation) & $59 \%$ \\
\hline F6(Intellectual-Cultural Orientation) & $62.16 \%$ \\
\hline F7(Active-Recreational Orientation) & $65.41 \%$ \\
\hline F8(Moral-Religious Emphasis) & $57.41 \%$ \\
\hline F9(Organization) & $59.5 \%$ \\
\hline F10(Control) & $59.83 \%$ \\
\hline
\end{tabular}

Table-6: Shows the Mean score and Standard deviation scores (SD) on the Severity Dependence scale (SDS) for Substance Abuse Disorder patients.

\begin{tabular}{|c|c|c|}
\hline Mean & N & SD \\
\hline 9.35 & 100 & 3.47 \\
\hline
\end{tabular}

Table-6, indicates that most of the patients showed high level of substance abuse on the Severity of Dependence Scale (SDS) $(\mathrm{m}=9.35, \mathrm{SD}=3.47)$.

Table-7: Shows the Mean scores and Standard deviation scores (SD) on Dimensions of Temperament Scale (DTS) for Substance abuse disorder patients.

\begin{tabular}{|c|c|c|c|}
\hline Dimensions & $\mathbf{N}$ & Mean & SD \\
\hline Sociability & & 10.37 & 1.39 \\
\hline Ascendant & & 7.59 & 1.28 \\
\hline Secretiveness & & 8.50 & 1.30 \\
\hline Reflective & & 8.47 & 1.40 \\
\hline Impulsivity & & 5.88 & .99 \\
\hline Placid & & 8.76 & 1.91 \\
\hline
\end{tabular}

\begin{tabular}{|c|c|c|c|}
\hline Accepting & \multirow[t]{9}{*}{100} & 4.96 & 1.02 \\
\hline Responsible & & 7.51 & 1.33 \\
\hline Vigorous & & 10.77 & 2.47 \\
\hline Co-operative & & 11.38 & 1.63 \\
\hline Persistence & & 6.78 & 1.28 \\
\hline Warmth & & 11.38 & 2.44 \\
\hline Aggressiveness & & 8.16 & 1.69 \\
\hline Tolerance & & 8.26 & 1.69 \\
\hline Tough-minded & & 5.72 & 1.45 \\
\hline
\end{tabular}

Table-7, indicates that the patients with high substance abuse had low mean score ( as discussed in the manual of DTS, Table no-6) on dimensions Vigorous $(\mathrm{m}=10.77$, $\mathrm{SD}=2.47)$, Warmth $\quad(\mathrm{m}=11.38, \quad \mathrm{SD}=2.44)$, Tolerance $(\mathrm{m}=8.26$, $\mathrm{SD}=1.69)$. The patients were average on dimensions Sociability $(\mathrm{m}=10.37, \mathrm{SD}=1.39)$, Ascendant $(\mathrm{m}=7.59, \mathrm{SD}=1.28)$, Secretiveness $(\mathrm{m}=8.50, \mathrm{SD}=1.30)$, Reflective $\quad(\mathrm{m}=8.47, \mathrm{SD}=1.40)$, Impulsivity $\quad(\mathrm{m}=5.88$, $\mathrm{SD}=.998)$, Placid $(\mathrm{m}=8.76, \mathrm{SD}=1.91)$, Accepting $(\mathrm{m}=4.96$, $\mathrm{SD}=1.02)$, Responsible $(\mathrm{m}=7.51, \mathrm{SD}=1.33)$, Cooperative $(\mathrm{m}=11.38, \mathrm{SD}=1.63)$, Persistence $(\mathrm{m}=6.78, \mathrm{SD}=1.28)$, Aggressiveness $\quad(\mathrm{m}=8.16, \quad \mathrm{SD}=1.69), \quad$ Tough-minded $(\mathrm{m}=5.72, \mathrm{SD}=1.45)$.

Figure no-IV: Showing the Percentage of Substance Abuse Disorder patients on different dimensions of Dimension in Temperament Scale (DT)

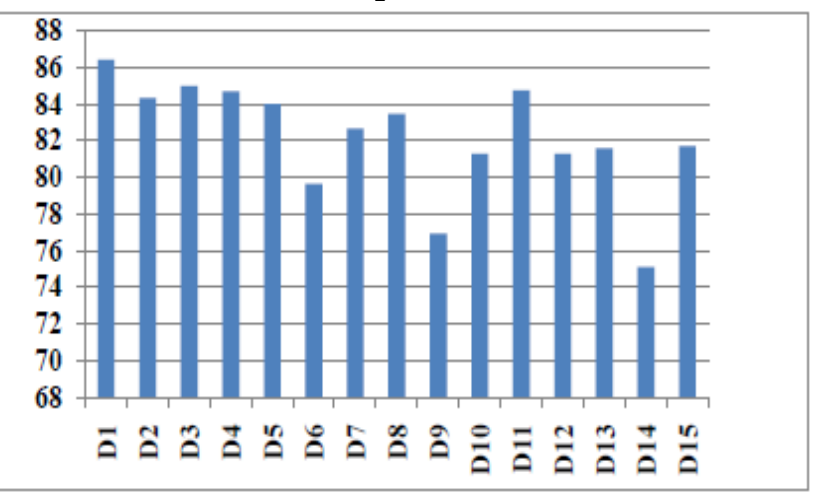

\begin{tabular}{|c|c|}
\hline D1 (Sociability) & $86.41 \%$ \\
\hline D2 (Ascendance) & $84.33 \%$ \\
\hline D3 (Secretiveness) & $85 \%$ \\
\hline D4 (Reflective) & $84.70 \%$ \\
\hline D5 (Impulsivity) & $84 \%$ \\
\hline D6 (Placid) & $79.63 \%$ \\
\hline D7 (Accepting) & $82.66 \%$ \\
\hline D8 (Responsible) & $83.44 \%$ \\
\hline D9 (Vigorous) & $76.92 \%$ \\
\hline D10 (Cooperative) & $81.28 \%$ \\
\hline D11 (Persistence) & $84.75 \%$ \\
\hline D12 (Warmth) & $81.28 \%$ \\
\hline D13 (Aggressiveness) & $81.60 \%$ \\
\hline D14 (Tolerance) & $75.09 \%$ \\
\hline D15 (Tough-minded) & $81.71 \%$ \\
\hline
\end{tabular}

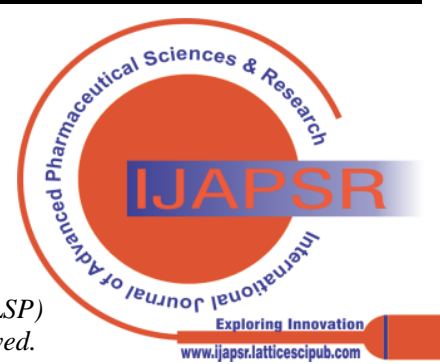


Association of Temperament, Family Environment and Personality Traits with the Symptoms of Depression and Substance Abuse Disorder: An Exploratory Research

Table-8: Shows the Mean scores and Standard deviation scores (SD) on NEO-FFI for Substance Abuse disorder patients.

\begin{tabular}{|c|c|c|c|}
\hline Dimensions & $\mathbf{N}$ & Mean & SD \\
\hline Neuroticism & \multirow{5}{*}{100} & 25.60 & 6.54 \\
\hline Extraversion & & 24.72 & 7.59 \\
\hline Openness & & 23.25 & 7.81 \\
\hline Agreeableness & & 23.46 & 8.21 \\
\hline Conscientiousness & & 24.49 & 8.78 \\
\hline
\end{tabular}

Table-8, indicates that the patients shows high mean score (as discussed in the NEO-FFI manual, Table no-B4) on domain Neuroticism $(\mathrm{m}=25.60, \mathrm{SD}=6.54)$ and low mean score on domains Extraversion $(\mathrm{m}=24.72, \mathrm{SD}=7.59)$, Openness $(\mathrm{m}=23.25, \mathrm{SD}=7.81)$, Agreeableness $(\mathrm{m}=23.46$, $\mathrm{SD}=8.21)$ and Conscientiousness $(\mathrm{m}=24.49, \mathrm{SD}=8.78)$.

Figure no- V: Showing Percentage of Substance Abuse Disorder patients on domains of NEO-FFI

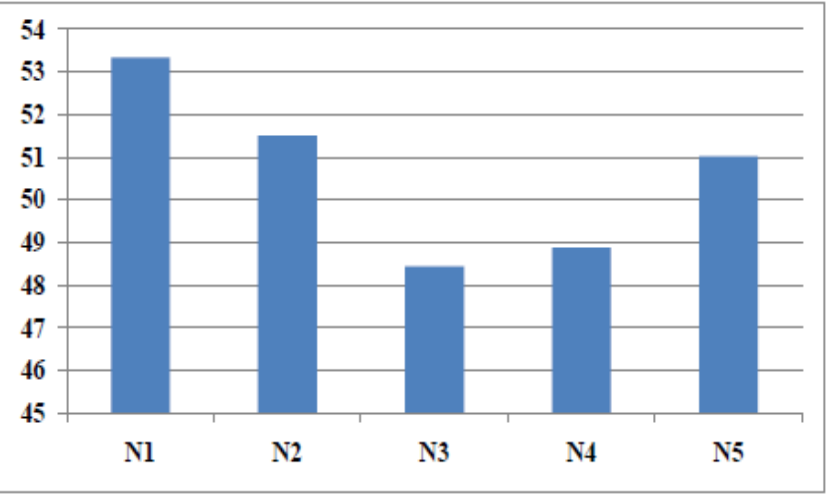

\begin{tabular}{|c|c|}
\hline N1 (Neuroticism) & $53.33 \%$ \\
\hline N2 (Extraversion) & $51.5 \%$ \\
\hline N3 (Openness) & $48.43 \%$ \\
\hline N4 (Agreeableness) & $48.87 \%$ \\
\hline N5 (Conscientiousness) & $51.02 \%$ \\
\hline
\end{tabular}

Table-9: Shows the Mean scores and Standard deviation scores(SD) on Family Environment Scale (FES) for Substance Abuse disorder patients.

\begin{tabular}{|c|c|c|c|}
\hline Dimensions & $\mathbf{N}$ & Mean & SD \\
\hline Cohesion & \multirow{5}{*}{ Expressiveness } & 53.81 & 8.11 \\
\cline { 4 - 4 } & & 62.36 & 6.51 \\
\cline { 4 - 4 } Conflict & 72.55 & 5.52 \\
\hline Independence & 53.72 & 9.91 \\
\hline \multirow{2nn}{*}{$\begin{array}{c}\text { Achievement } \\
\text { Orientation }\end{array}$} & 63.28 & 7.44 \\
\cline { 4 - 4 } & & & \\
\hline
\end{tabular}

\begin{tabular}{|c|c|c|c|}
\hline $\begin{array}{l}\text { Intellectual- } \\
\text { Cultural } \\
\text { Orientation }\end{array}$ & 100 & 60.61 & 7.24 \\
\hline $\begin{array}{c}\text { Active- } \\
\text { Recreational } \\
\text { Orientation }\end{array}$ & & 64.24 & 4.63 \\
\hline $\begin{array}{c}\text { Moral- } \\
\text { Religious } \\
\text { Emphasis }\end{array}$ & & 65.90 & 5.64 \\
\hline Organization & & 61.90 & 7.21 \\
\hline Control & & 67.23 & 7.82 \\
\hline
\end{tabular}

Table-9, indicates the mean score and SD of the patients (as discussed in the manual of FES by making few casestudies the base for the analysis and interpretation) on subscales Cohesion $(\mathrm{m}=53.81, \mathrm{SD}=8.11)$, Expressiveness $(\mathrm{m}=62.36, \quad \mathrm{SD}=6.51)$, Conflicts $\quad(\mathrm{m}=72.55, \quad \mathrm{SD}=5.52)$, Independence $\quad(\mathrm{m}=53.72, \quad \mathrm{SD}=9.91), \quad$ Achievement Orientation $\quad(\mathrm{m}=63.28, \quad \mathrm{SD}=7.44), \quad$ Intellectual-Cultural Orientation $\quad(\mathrm{m}=60.61, \quad \mathrm{SD}=7.24), \quad$ Active-Recreational Orientation $\quad(\mathrm{m}=64.24, \quad \mathrm{SD}=4.63), \quad$ Moral-Religious Emphasis $(\mathrm{m}=65.90, \mathrm{SD}=5.64)$, Organization $(\mathrm{m}=61.90$, $\mathrm{SD}=7.21)$ and Control $(\mathrm{m}=67.23, \mathrm{SD}=7.82)$.

Figure no- VI: Showing the Percentage of Substance Abuse Disorder patients on FES

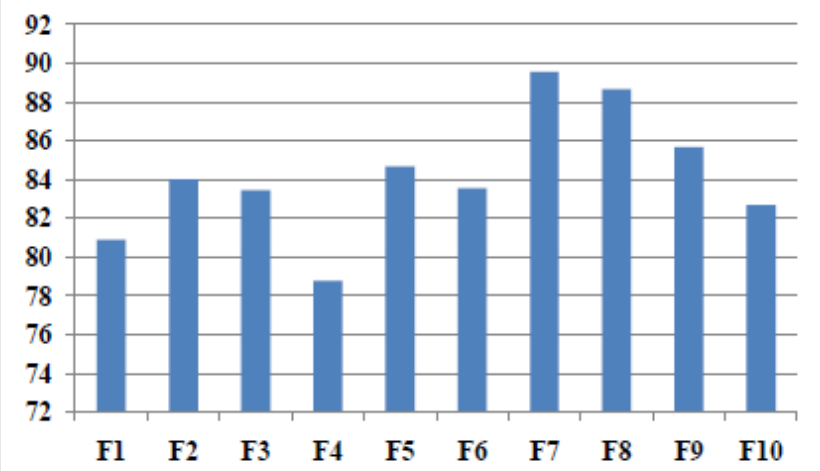

\begin{tabular}{|c|c|}
\hline F1 (Cohesion) & $80.88 \%$ \\
\hline F2(Extraversion) & $84 \%$ \\
\hline F3(Conflict) & $83.44 \%$ \\
\hline F4(Independence) & $78.77 \%$ \\
\hline $\begin{array}{l}\text { F5(Achievement } \\
\text { Orientation) }\end{array}$ & $84.66 \%$ \\
\hline $\begin{array}{c}\text { F6(Intellectual-Cultural } \\
\text { Orientation) }\end{array}$ & $83.55 \%$ \\
\hline $\begin{array}{c}\text { F7(Active-Recreational } \\
\text { Orientation) }\end{array}$ & $89.55 \%$ \\
\hline $\begin{array}{c}\text { F8(Moral-Religious } \\
\text { Emphasis) }\end{array}$ & $88.66 \%$ \\
\hline F9(Organization) & $85.66 \%$ \\
\hline F10(Control) & 82.66667 \\
\hline
\end{tabular}




\section{DISCUSSION}

The study was conducted to establish the association between temperament, family environment and personality traits with psychiatric symptoms of depression and substance abuse disorder patients. To give a valid justification to the present study an extensive review was carried out to identity the relevant already existing knowledge related to the present topic of research.

\section{Discussion for the Obtained Results:}

Table-1 depicts socio-demographic details of all the patients, giving the information about the percentage of the patients lying under the inclusion criteria (Age, Education, Marital status, and Residence). It can inferred that most of the patients belonging from urban area, educated (literate), married and of age ranging between 31-40 are going through rough phase of their life and are being prone to depression and substance abuse, in accordance with the present research.

\section{For Depression Patients:-}

The obtained result (shown in Table no-2) indicates that most of the patients were at moderate level of depression. It can be inferred from the obtained result (shown in Table no.3) that the patients do not have the quality of being social, i.e., they did not like to meet and spend time with others; they rather prefer to be alone. They hide their feelings, thoughts, intensions and actions from other people. They remain very secretive as they possess secretive characteristics in them, so they are not open to any discussion, i.e., they do not want to discuss anything regarding their thoughts. They lack the spirit of energy and strength in them. They avoid indulging with people, which indicates that they lack the characteristics of affection and kindness. They are aggressive in their nature; they show hostile or violent behaviour. It is bad when it comes to tolerance, their level of tolerance is very low, and they cannot tolerate or stand to what they dislike or disagree with.

As the patients were taken from rehabilitation centre so at the time of data collection the patients were already under remission period, i.e., they were under medication and were also given psycho-social interventions, as mentioned in the procedure. It may be because of this reason that the subjects showed slight improvement in them and have scored average on few dimensions of temperament scale (Ascendant, Impulsivity, Placid, Responsible, Persistence, and Tough-minded). Patients have scored high mean on the dimension Accepting. In accordance to the obtained result, it can be said that there has been slights improvement in the behaviour of the patients which may be due to the counselling, vocational and occupational training, psychotherapy and medication that are being given to them. The patients were trying to behave in rational manner, were avoiding the habit of easily becoming upset or angry, showed sense of commitment towards whatever they did. They have started trying to face the reality, the fact in spite difficulty or opposition. The characteristics of sense of taking initiative for something has slowly started to develop in them.

In spite of slight improvement seen in the patients, the characteristics like negativity, disapproval, hostility, distrust, reluctance, suspicion, hesitation, etc are being possessed by them and the level of negativity in them is high.
$80.66 \%$ of patients showed low mean on dimension Sociability, $74.3 \%$ on dimension Secretiveness, $79.7 \%$ on dimension Reflective, $76.85 \%$ on Vigorous, $77 \%$ on Cooperative, $77.71 \%$ on Warmth, $76.6 \%$ on Aggressiveness and $77.18 \%$ on dimension tolerance. $81.77 \%$ of patients were average on Ascendant, 78\% on Impulsivity, $76.18 \%$ on Placid, $80.33 \%$ on Responsible, $82 \%$ on Persistence and $78.57 \%$ on Tough-minded. $84.66 \%$ of patients had high mean score on dimension Accepting.

A.Ambrosini, G.Stanghellini and A.Raballo (2014), conducted a qualitative descriptive study where they concluded that temperament and personality makes a person vulnerable to mood disorder making a person possess the melancholic type of personality. Hence, concluding that both (temperament and personality) are associated with depressive disorder. Thus, the present study supports the previous study.

As per the obtained result (shown in Table no- 4) core of neuroticism dimension is the general tendency to experience negative effects such as fear, sadness, embarrassments, anger, guilt, and disgust. High mean score on neuroticism dimension indicates that the subjects are less able to control their impulses, have poor coping skills, is prone to feeling sad, lonely and dejected. They have the feeling of guilt, sadness, hopelessness. They easily get discouraged. They are dependent on others and easily get panicked when facing emergency situations. The subjects also have apprehensive, fearful, nervousness and jittery characteristics or traits in them. The patients have scored low mean on Extraversion, Openness, Agreeableness, and Conscientiousness indicates that they tend to be conventional in behaviour and conservation in their outlook. Their emotional responses are somewhat muted. The patients have a low level of energy and prefer a slow and steady pace. They are not necessarily unhappy, they are less exuberant (cheerful, excited, ebullient) and high-spirited. They prefer to stay in the background and let others do the talking. They show narcissist and anti-social characteristics in them. They hardly control their impulses and desire. Their will power is not strong. They are not reliable and have a procrastinating nature when it comes to work. They do not have ambition. The patients have low self-esteem, low self-confidence and are self- centred. They have hardheads i.e., they cannot be influenced by appeal to pity. They often speak and act without thinking, their thought process is irrational.

Among depression patients, 55\% of the patients have high mean score on Neuroticism domain. $49.5 \%$ of the patients have low mean score on domain Extraversion, $51.68 \%$ on Openness, $50.56 \%$ on Agreeableness, and $50.39 \%$ on Conscientiousness.

The study conducted by Sattar Kikhavani and Hamid Taghinejad (2015), both the studies concluded or found that high neuroticism and low extraversion as a component of depression or makes an individual more vulnerable to depression. Thus, the present research supports the previous studies.

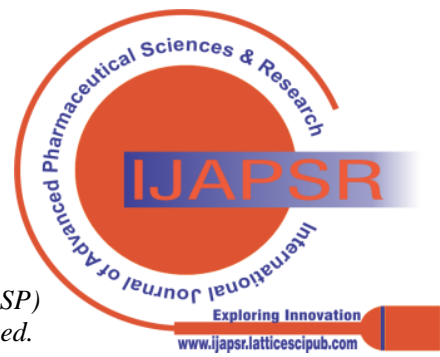




\section{Association of Temperament, Family Environment and Personality Traits with the Symptoms of Depression and Substance Abuse Disorder: An Exploratory Research}

To see the family profile of depression patients, FES was used. The result obtained on FES (as the result shown in the Table no- 5) has been interpreted as discussed in the manual by making the case-study mentioned in the manual as the base. According to the patient's perception, relationship with their family members is poor. The result indicates the high level of conflict. There was moderate level of Cohesion and Independence in the family. And the patients have high mean score on subscales Expressiveness, Achievement orientation, Intellectual-Cultural orientation, ActiveRecreational orientation, Moral-Religious Emphasis, Organization, and Control. This gives an idea that there was conflict between the patients and their family members, the families has high expectation from the patients regarding their commitment towards their family and their career. The sense of togetherness between the patients and their family members was not too much. The family members of the patients were quiet religious and had high moral values. The but according to the set rules and regulation and procedures of family, which kept the patients in dilemma whether to be assertive or to remain reserved which ultimately resulted in conflict between the family members thought and patients thought. The result here indicates as depicted by patients that their families come under Conflict Oriented family.

Among depression patients, $82.88 \%$ of them have been average on subscales Cohesion and $61.16 \%$ on Independence. $60.58 \%$ of patients depicted high mean score on subscale Conflict, $60.66 \%$ on Expressiveness, $59 \%$ on Achievement orientation, and $62.16 \%$ on IntellectualCultural orientation, $65.41 \%$ on Active-Recreational orientation, 57.41\% on Moral-Religious Emphasis, 59.5\% on Organization and 59.83\% on Control.

Paria Ahookhosh, Bahman Bahmani, Ali Asgari and Hossein Hassanian Moghaddam (2017) conducted a study and found that family cohesion and expressiveness were stronger predictors of suicidal ideation than family conflict. Hence, family cohesion and family expressiveness act as predictive factors against depression, hopelessness, anxiety and suicide ideation. Thus, the present research contradicts the mentioned earlier study as in the present research conflict is found to be the predictor of depression.

\section{For Substance Abuse Disorder Patients:-}

Table-6, indicates that most of the patients were on higher side of substance abuse $(m=9.35, S D=3.47)$. From the obtained result (shown in Table no-7), the patients had low mean score on dimension Vigorous, Warmth and Tolerance; which indicated that the patients generally did not have affection or kindness for other peoples. They had low level of enthusiasm. Generally they have low energy. They do not hesitate in expressing their opinion or behaviour towards those things which they dislike or disagree with and this is because of their low tolerance level. They are not capable enough to take proper decisions and even if they attempt to take or make any decision they are not strong enough to stand for the decisions taken or made by them. They are not that type of person who gets easily mixed or who gets mingled with other people as they generally do not have the sense of affection and kindness for others. Due to their habit of taking substances makes have an unhealthy thought process or irrational thought process. The patients were average on dimensions Sociability, patients were allowed to express their thoughts and feelings

Ascendant, Secretiveness, Reflective, Impulsivity, Placid, Accepting, Responsible, Cooperative, Persistence, and Aggressiveness, Tough-minded; indicating that the patients were trying to becoming liberal, i.e., they started spending timing with others, were showing their agreement towards sharing their thoughts and feeling with those with whom they have confidence. They started showing calm behaviour, less aggressiveness, less upset behaviour. They were trying to sound rational as far as their thought and behaviour were concerned. Will power to show acceptance for the reality was seen in them. All this slight improvement that was seen in them was may be because of the medication and the psycho-social interventions that they were receiving.

Among substance abuse disorder patients $76.92 \%$ of patients have low mean score on dimension Vigorous, $81.28 \%$ on Warmth and $75.09 \%$ on Tolerance. $86.41 \%$ of patients were on average on dimension of Sociability, 84.33\% on Ascendant, 85\% on Secretiveness, $84.7 \%$ on Reflective, $84 \%$ on Impulsivity, $79.63 \%$ on Placid, $82.66 \%$ on Accepting, $83.44 \%$ on Responsible, $81.28 \%$ on Cooperative, $84.75 \%$ on Persistence, $81.6 \%$ on Aggressiveness, and $81.71 \%$ on Tough-minded.

Sonali Jhanjee (Evidence based Psychosocial Intervention in Substance Use, 2014) have clearly mentioned that psychological treatment is more effective when it is prescribed with substitute (medication) than when medication or psychological treatment is used alone for changing patients substance using behaviour. Thus, the present research supports the mentioned point in the earlier study.

From the results (shown in Table no-8) it can be inferred that the patients have the characteristics of high negative affects like anxiety, nervousness, fearful in them. They had the tendency of getting angry easily. They had sense of guilt, hopelessness in them. They are unable to control their craving and desires. They are very impulsive and this can be perceived through the strong craving that they cannot resist. They experience free-floating anxiety. All this can be said about the patients because they had high mean score on domain Neuroticism. Low mean score on domains Extraversion, Openness, Agreeableness, Conscientiousness; this indicates that the patients are not necessarily sluggish or lazy but are more of leisurely type. They have a rough behaviour towards other people. They usually prefer to stay alone and lonely. The low score indicates that the patients tend to be cynical, i.e., they do not easily trust anyone and sceptical, i.e., they doubt other people's behaviour that they approach them because of their selfish motives and not because they really care for them (the patients). They are aggressive, competitive, unorganised people. Without thinking about or considering the consequences they speak and act.

$53.33 \%$ of patients have scored high mean on domain Neuroticism. 51.5\% have scored low mean on domain Extraversion, $48.43 \%$ on Openness, $48.87 \%$ on Agreeableness, and $51.02 \%$ on Conscientiousness.

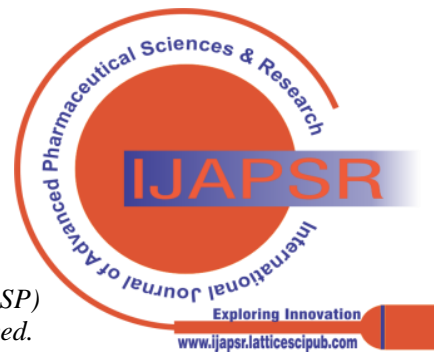


A study was conducted by Isaac Rahimian Boogar, Sayed Mosa Tabatabaee and Jalileh Tosi (2014), it was seen that male sex and neuroticism had a significant positive role in predicting positive attitude towards substance abuse. Lower agreeableness, higher neuroticism, diminished openness low socio-economic status and male sex might make university students more inclined towards substance abuse.

Another study was conducted by Charu Dubey, Meenakshi Arora, Sanjay Gupta and Bipin Kumar (2010), it was noticed as a result that the Non Substance Abused group scored higher on Openness and Conscientiousness scored significantly lower on Extraversion and Neuroticism domain of the Five Factor Model of Personality as compared o the Substance Abused group. No significant difference was obtained on agreeableness domain of personality. Thus, the present research supports the mentioned previous studies.

The family profile depicted by the patients through the obtained result (shown in Table no- 9) indicates that the patients families are quiet cohesive and well-organised. The family of the patients focuses of cultural and recreational activities making it a burden for the patients to meet the expectations of their family members. The members of the family were very religious with high moral values. Moderate to high score on subscales Expressiveness and Independence, indicates that the members of the family were allowed to express their feelings, they were allowed to be self-sufficient enough to make their own decisions but in the set frame work that were made by the family members itself and this is the reason that the patients have high mean score on subscale Control. There was high level of conflict between the patients and their family members as per the perception of the patient. There was high level of conflict between the patients and their family members because the patients were allowed to express their feelings and thought but at the same time the feelings and thoughts being expressed by them should not be against what the other family member think is right, i.e., it should be under the set frame of rules and norms and moral values made by the family members themselves, which creates an conflicting environment in the family. Thus, the family profile being depicted by the patients about their current family environment is Conflict Oriented family.

It was seen that $80.88 \%$ of patients were average on subscale Cohesion and $78.77 \%$ on Independence. $83.44 \%$ of patients scored high mean on subscale Conflict, $84 \%$ on Expressiveness, $84.66 \%$ on Achievement orientation, $83.55 \%$ on Intellectual-Cultural orientation, $89.55 \%$ on Active-Recreational orientation, $88.66 \%$ on Moral-Religious emphasis, $85.66 \%$ on Organisation and $82.66 \%$ on Control.

Narendra Kumar Singh, Dipanjan Bhattacharjee, Nishat Goyal, Sanjay Kumar Munda and S.H.Nizamie (2012), conducted a study and revealed spouse's lower level of family environment in the domain of expressiveness as compared to parents and siblings of alcohol dependence. Thus, the present research contradicts the mentioned earlier study.

\section{CONCLUSION}

After sufficient analysis and an in depth study followed by necessary interpretation of the results obtained regarding the underlying variables it can be successfully concluded that the variables (Temperament, Family environment and Personality traits) and the psychiatric symptoms of depression and substance abuse disorder are interlinked or associated with each other.

In accordance to the results obtained and after the due analysis it can be said that the patients experienced the psychiatric symptoms like loss of interest in daily activities, loss of energy or fatigue, strong feeling of worthlessness or guilt, impaired judgement or indecisiveness, impulsivity, anger, depressed mood, undesirable behaviour or grossly bizarre behaviour, relationship difficulty, concentration problem, feeling lonely or dejected, loss of pleasure, poor social performance under the research conducted.

\section{Limitations:}

1. Large sample size should be taken in to consideration.

2. Other gender like females and transgender should also be taken under consideration.

3. Other variables like anxiety, OCD, etc should also be taken

4. Others psychological disorders should also be included in the research.

5. Patients with different psychiatric illness should be taken into account and then their associations or comparison with each other should be done.

\section{REFERENCES}

1. Ahookhosh, P., Bahmani, B., Asgari, A., \&HassanianMoghaddam, H. (2017). Family relationships and suicide ideation: the mediating roles of anxiety, hopelessness, and depression in adolescents. International journal of high risk behaviors and addiction, 6(1). [CrossRef]

2. Ambrosini, A., Stanghellini, G., \&Raballo, A. (2014). Temperament, personality and the vulnerability to mood disorders. The case of the melancholic type of personality. Journal of Psychopathology, 20, 393-403.

3. Beck,A.T., Steer,R.A., \& Garbin, M.G. (1988) Psychometric properties of the Beck Depression Inventory: Twenty-Five years of evalution. Clinical Psychology Review, 8(1),77-100 [CrossRef]

4. Boogar, I. R., Tabatabaee, S. M., \&Tosi, J. (2014). Attitude to substance abuse: do personality and socio-demographic factors matter?. International journal of high risk behaviors\& addiction, 3(3). [CrossRef]

5. Chadha, N. K. \&Chandna, Sunanda (1984). Dimensions of temperament scale. NationalPsychologicalCorporation.

6. Costa, P. T., \& McCrae, R. R. (1985). The NEO personality Inventory. [CrossRef]

7. Dubey, C., Arora, M., Gupta, S., \& Kumar, B. (2010). Five Factor correlates: A comparison of substance abusers and non-substance abusers. Journal of the Indian Academy of Applied Psychology.

8. Gilhooly, T., Bergman, A. J., Stieber, J., \& Brown, E. J. (2018) Posttraumatic stress disorder symptoms, family environment, and substance abuse symptoms in emerging adults. Journal of Child \& Adolescent Substance Abuse, 27(3), 196-209. [CrossRef]

9. Gossop M, Darke S, Griffiths P, Hando J, Powis B, Hall W, Strang J. The Severity of Dependence Scale (SDS): psychometric properties of the SDS in English and Australian samples of heroin, cocaine and amphetamine users. Addiction. 1995 May;90(5):607-14. doi: 10.1046/j.1360-0443.1995.9056072.x. PMID: 7795497. [CrossRef]

10. Jhanjee, S. (2014). Evidence based psychosocial interventions in substance use. Indian journal of psychological medicine, 36(2), 112118. [CrossRef]

11. Jokela, M., \&Keltikangas-Järvinen, L. (2011). The association between low socioeconomic status and depressive symptoms depends on temperament and personality traits. Personality and Individual Differences, 51(3), 302-308. [CrossRef]

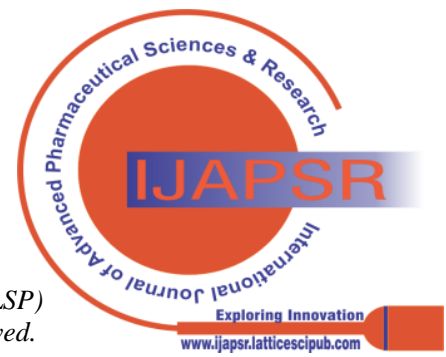


12. Kikhavani, S., \&Taghinejad, H. (2015). Personality factor as a predictor of depression score among depressed and CHD patients. Journal of clinical and diagnostic research: JCDR, 9(10), VC04. [CrossRef]

13. Moos, R. H., \& Moos, B. S. (1974). Family environment scale. Palo Alto, CA: Consulting Psychologists Press. [CrossRef]

14. Robison, E. J., Shankman, S. A., \& McFarland, B. R. (2009) Independent associations between personality traits and clinical characteristics of depression. The Journal of nervous and mental disease, 197(7), 476. [CrossRef]

15. Singh NK, Bhattacharjee D, Goyal N, Munda SK, Nizamie SH (2012) Perceive Family Environment among Parents, Spouses and Siblings of Alcohol Dependence Patients: A Comparative Study. J Addict Res Ther 3:126.doi; 10.4172/2155-6105.100016

16. Sutin, A. R., Stephan, Y., Luchetti, M., \&Terracciano, A. (2019). The prospective association between personality traits and persistent pain and opioid medication use. Journal of psychosomatic research, 123, 109721. [CrossRef]

\section{AUTHORS PROFILE}

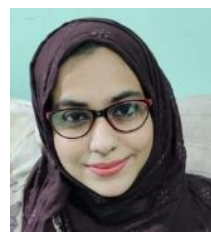

Dr. Kaukab Imam, obtained my schooling education from Girls' High School, Allahabad, following which I enrolled myself for Graduation in English Honours from Aligarh Muslim University. As a result of having an immense interest in psychology for a long period of time I enrolled for my Post Graduation in Psychology from AMU following my graduation. I then decided to further explore my horizons in Psychology by pursuing Ph.D. in the same from AMU where I gained an in-depth knowledge in this field. I have papers published in my name in National as well as International peer reviewed journals and have also attended several National and International conferences. My interests majorly lie towards the clinical aspects of Psychology and counselling and I strive hard to impart all the knowledge I have gained during this journey so far to as many people interested as I can have access to.

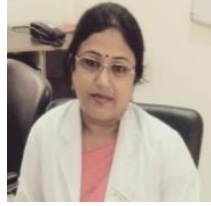

Dr. Deoshree Akhouri, is a renowned Clinical Psychologist and Associate Professor (Clinical Psychology) in the Department of Psychiatry, Jawaharlal Nehru Medical College and Hospital (JNMCH), Aligarh Muslim University (AMU), Aligarh. She has published more than 40 research papers in peer reviewed National and International Journals. She has published four chapters in national and international book. She is interested in Neuropsychological Assessment, Psychotherapy, Hypnosis, MBRT, etc. She is also interested and eager to contribute in Geriatric, Adult and Forensic Psychiatry. She is MD/PhD Supervisor. She is associated with different professional organizations, Somatic Inkblot Society, Indian Association of Clinical Psychologists, Indian Psychiatric Society, Association of Industrial Psychiatry of India, News letter Hospital Infection Society India-Aligarh Chapter and Medical Education Unit, JNMCH, AMU etc. She is resource person in various academic programs. She is chaired national and international conferences. She got various awards in conferences.

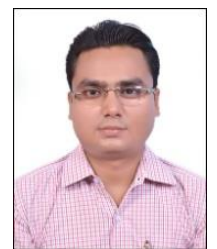

Dr. Shravan Kumar, did his MBBS and MD (Psychiatry) from Jawaharlal Nehru Medical College, AMU, Aligarh. After MD I was Senior Residency (3 years) in the department of Psychiatry at the same Medical College. He has a keen interest in academics and research. More than half dozen of his work is published in various national and international journals. His thrust areas are Neuropsychiatry, General Psychiatry and Geriatric Psychiatry.

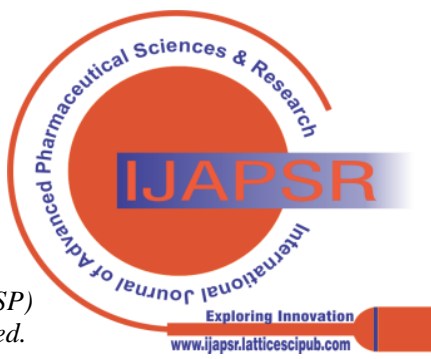

